\title{
Distinct functions of neuromedin $u$ and neuromedin s in orange-spotted grouper
}

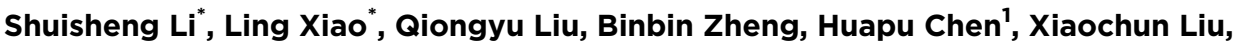 \\ Yong Zhang and Haoran Lin
}

State Key Laboratory of Biocontrol, Institute of Aquatic Economic Animals, and the Guangdong Province Key Laboratory for Aquatic Economic Animals, School of Life Sciences, Sun Yat-Sen University, Guangzhou 510275, China

${ }^{1}$ Fisheries College, Guangdong Ocean University, Zhanjiang 524088, China

*(S Li and L Xiao contributed equally to this work)
Correspondence should be addressed to $\mathrm{Y}$ Zhang or $\mathrm{H}$ Chen Emails

Isszy@mail.sysu.edu.cn or chpsysu@hotmail.com

\begin{abstract}
Neuromedin U (NMU) and neuromedin S (NMS) play inhibitory roles in the regulation of food intake and energy homeostasis in mammals. However, their functions are not clearly established in teleost fish. In the present study, $n m u$ and $n m s$ homologs were identified in several fish species. Subsequently, their cDNA sequences were cloned from the orange-spotted grouper (Epinephelus coioides). Sequence analysis showed that the orangespotted grouper Nmu proprotein contains a 21-amino acid mature Nmu peptide (Nmu-21). The Nms proprotein lost the typical mature Nms peptide, but it retains a putative 34-amino acid peptide (Nmsrp). In situ hybridization revealed that $n m u$ - and $n m s$-expressing cells are mainly localized in the hypothalamic regions associated with appetite regulation. Food deprivation decreased the hypothalamic nmu mRNA levels but induced an increase of $n m s$ mRNA levels. Periprandial expression analysis showed that hypothalamic expression of $n m u$ increased significantly at $3 \mathrm{~h}$ post-feeding, while $\mathrm{nm}$ s expression was elevated at the normal feeding time. I.p. injection of synthetic Nmu-21 peptide suppressed the hypothalamic neuropeptide y (npy) expression, while Nmsrp administration significantly increased the expression of $n p y$ and orexin in orange-spotted grouper. Furthermore, the mRNA levels of LH beta subunit (Ih $\beta$ ) and $g h$ in the pituitary were significantly down-regulated after Nmu-21 peptide administration, while Nmsrp was able to significantly stimulate the expression of FSH beta subunit ( $f s h \beta$, prolactin ( $p r l)$, and somatolaction $(s l)$. Our results indicate that $n m u$ and $n m s$ possess distinct neuroendocrine functions and pituitary functions in the orange spotted grouper.
\end{abstract}

Key Words $\rightarrow n m u$

- nms

- structural diversity

- feeding regulation

- pituitary function
Journal of Molecular

Endocrinology

(2015) 55, 95-106

\section{Introduction}

Neuromedin U (NMU), first isolated from porcine spinal cord, was named for its ability to cause uterine smooth muscle contraction (Minamino et al. 1985). Neuromedin S (NMS), first identified in rat brain, was named for its specific expression in the suprachiasmatic nucleus of the
(C) 2015 Society for Endocrinology Printed in Great Britain hypothalamus (Mori et al. 2005). NMU and NMS are structurally related neuropeptides, bearing seven identical amino acid residues at their C-terminus, and they activate the same G-protein-coupled receptors, NMUR1 and NMUR2 (Mitchell et al. 2009). Both NM peptides have

Published by Bioscientifica Ltd 
now been implicated in a range of physiological activities, including smooth muscle contraction, circadian rhythm, and gonadotropic axis regulation (Mori et al. 2008, Budhiraja \& Chugh 2009).

Evidence has also demonstrated that NMU and NMS play important roles in the regulation of feeding behavior and energy homeostasis in mammals (Howard et al. 2000, Hanada et al. 2004, Ida et al. 2005, Shousha et al. 2006, Peier et al. 2009). Central administration of NMU decreased food intake and resulted in loss of body weight in rodents, but also increased locomotor activities and body temperature (Howard et al. 2000, Ivanov et al. 2002, Peier et al. 2009). Mice deficient in Nmu are hyperphagic and obese with reduced energy expenditure (Hanada et al. 2004), while transgenic overexpression of $\mathrm{Nmu}$ can lead to leanness and hypophagia in mice (Kowalski et al. 2005). Despite low expression of NMS in the brain regions associated with feeding control, i.c.v. injections of NMS cause a decrease of food intake in rats (Ida et al. 2005). Recently, the actions of NMU and NMS in the control of feeding behavior have been clarified. The anorexigenic effects of NMU and NMS have been observed in WT and $\mathrm{Nmur}^{-/-}$mice, but were absent in $\mathrm{Nmur}^{-/-}$mice, indicating that the roles of these two peptides in feeding regulation are mediated by NMUR2 (Peier et al. 2009).

High expression levels of NMU and NMS are also observed in the pituitary in mammals (Fujii et al. 2000, Mori et al. 2005). The roles of NMU and NMS on gonadotropic hormone secretion have received much attention. Yet there is much controversy about their actions on gonadotropin release. Some studies showed that NMU and NMS suppressed luteinizing hormone (LH) release (Quan et al. 2004, Yang et al. 2010), but others found that they had stimulatory actions on LH secretion (Vigo et al. 2007a,b). On the other hand, their involvements in the regulation of other pituitary hormones are largely unclear.

In teleost fish, however, the significance of $n m u$ and $n m s$ in feeding regulation and pituitary gland remains to be established. Only one report has found that i.c.v.injected Nmu peptide could suppress food intake in goldfish (Maruyama et al. 2008). The function of $n m s$ gene has not been characterized in fish species thus far. Given that fish are composed of evolutionarily divergent species, further studies in different species are highly warranted to reveal their roles in the regulation of feeding and pituitary hormone secretion. In this study, we have therefore identified the $n m u$ and $n m s$ genes and analyzed their protein structures in teleost fish. Then, we investigated their roles in feeding and pituitary hormones regulation in the orange-spotted grouper (Epinephelus coioides), which is a commercially important marine fish and is widely cultured in South East Asia.

\section{Materials and methods}

\section{Data mining and genomic synteny analysis}

To identify the $n m u$ and $n m s$ genes in teleost fish, tblastn was performed to search the Ensemble and NCBI genome databases, as well as the EST database at NCBI using the mammalian NMU and NMS peptides as the query sequences. Genomic synteny analysis was performed on the Ensemble genome database. The obtained $n m u$ and $n m s$ gene sequences were searched against the genomes of human, chicken, zebrafish, and Takifugu, and the chromosomal locations of the $n m u$ and $n m s$ genes were identified in these species. Genes around the fish $n m u$ and $n m s$ were used to search for orthologs in the genome databases of human and chicken.

\section{Animals and chemicals}

Orange-spotted groupers were obtained from Daya Bay Aquaculture Center (Guangdong, China). Since orangespotted grouper is a protogynous hermaphroditic fish in which individuals mature as female first and start to change sex around the age of 7 years, all fish used in this study were female. The fish were anesthetized with $0.05 \%$ tricaine methanesulfonate and sacrificed by decapitation. Tissue samples were collected immediately and snapfrozen in liquid nitrogen. All animal experiments were conducted in accordance with the guidelines and approval of the respective Animal Research and Ethics Committees of Sun Yat-Sen University.

Peptides corresponding to orange-spotted grouper Nmu-21 and NMS-related peptide (Nmsrp) were synthesized by GL Biochemistry (Shanghai, China). The purity was $\geq 95 \%$ as determined by analytical HPLC.

\section{Molecular cloning of $n m u$ and $n m s$ CDNAs in orange-spotted grouper and sequence analysis}

Total RNA from the brain of orange-spotted groupers was prepared using TRIzol reagent (Invitrogen). One microgram of isolated RNA was used to synthesize the first-strand cDNA using the ReverTra Ace-First-strand cDNA Synthesis Kit (Toyobo, Osaka, Japan). Then GeneRacer Kit (Invitrogen) was used to amplify the full-length cDNA sequence by combining the gene-degenerated primers or specific primers

Published by Bioscientifica Ltd. 
and $5^{\prime}$ - or $3^{\prime}$-adaptor primers. Both $5^{\prime}$ - and $3^{\prime}$-end sequences were amplified by two rounds of PCR respectively. All primers used in the study are listed in Supplementary Table 1, see section on supplementary data given at the end of this article.

PCR amplifications were performed with an initial denaturation at $94^{\circ} \mathrm{C}$ for $3 \mathrm{~min}$, followed by 40 cycles of $94{ }^{\circ} \mathrm{C}$ for $15 \mathrm{~s}, 53-58{ }^{\circ} \mathrm{C}$ for $15 \mathrm{~s}$, and $72{ }^{\circ} \mathrm{C}$ for $35-70 \mathrm{~s}$. The reaction was terminated by a final extension cycle of 5 min at $72{ }^{\circ} \mathrm{C}$.

The signal peptide and the neuropeptide prohormone cleavage sites of $\mathrm{Nmu}$ and $\mathrm{Nms}$ precursors were predicted using Signal P3.0 and Neuropred Software respectively (Bendtsen et al. 2004, Southey et al. 2006). Nmu and Nms amino acid sequences were aligned using Clustal X1.81 (Thompson et al. 1994).

A phylogenetic tree was constructed with MEGA3.1 using neighbor-joining with default settings (Kumar et al. 2004). One thousand bootstrap replications were conducted.

\section{RT-PCR analysis of the tissue distribution of $n m u$ and $n m s$ mRNA in the orange-spotted grouper}

The tissue expression patterns of $n m u$ and $n m s$ mRNA in various tissues were analyzed by RT-PCR. Total RNA was isolated from 11 tissues, i.e., brain, pituitary, liver, stomach, intestine, muscle, kidney, spleen, gill, heart, and ovary. One microgram of total RNA from each tissue was digested with DNase I (Invitrogen) and reversetranscribed into cDNA as described above. Mock RT reactions without reverse transcriptase were used as negative controls. The primers are listed in Supplementary Table 1. The PCRs were performed as described above.

\section{Localization analysis of $n m u$ and $n m s$ mRNA in the brain of the orange-spotted grouper}

To investigate the distribution of $n m u$ and $n m s$ cells in the brain of the orange-spotted grouper, frozen sections were used for in situ hybridization assays. Briefly, the whole brain was fixed with $4 \%$ paraformaldehyde (PFA) in PBS, kept at $4{ }^{\circ} \mathrm{C}$ overnight and dehydrated in 30\% sucrose-PBS buffer for $12 \mathrm{~h}$ at $4{ }^{\circ} \mathrm{C}$. The brain was then embedded in optimal cutting temperature compound (Sakura Finetek, Torrance CA, USA), and cross-sections were cut serially at $10 \mu \mathrm{m}$ thick with frozen cryotomy (Leica 1900, Wetzlar, Germany). The sections were thaw-mounted onto aminopropylsilanetreated glass slides and dried in an oven.

The RNA probe sequences covering the open reading frame (ORF) sequence of the grouper's $n m u$ and $n m s$ were amplified with primers listed in Supplementary Table 1 and constructed into the pGEM-T easy vector (Promega). Sense and antisense probes were synthesized with a DIG RNA Labeling Mix (Roche). The slides were permeabilized three times with PBS for $10 \mathrm{~min}$ and treated with proteinase $\mathrm{K}$ in PBS $(10 \mu \mathrm{g} / \mathrm{ml})$ for $15 \mathrm{~min}$ at $37^{\circ} \mathrm{C}$, refixed in $4 \%$ PFA, prehybridized at $55^{\circ} \mathrm{C}$ for $1 \mathrm{~h}$ and hybridized with sense and antisense probes for $n m u$ and $n m s$ at $55^{\circ} \mathrm{C}$ overnight. After hybridization, sections were washed twice in $2 \times$ salinesodium citrate (SSC) at room temperature for $15 \mathrm{~min}$, and in $1 \times$ SSC and $0.1 \times$ SSC at $55^{\circ} \mathrm{C}$ for $1 \mathrm{~h}$ sequentially. The hybridization signals were detected with an alkaline phosphatase-conjugated anti-DIG antibody and were visualized with nitroblue tetrazolium chloride/5-bromo-4-chloro-3indolyl phosphate substrate solution (Roche). The images were viewed with a Nikon eclipse Ni (Nikon, Japan) optical microscope.

\section{Analysis of the changes in $n m u$ and $n m s$ mRNA levels under different feeding regimes}

The experiments were performed in the Daya Bay Aquaculture Center. Fish (body weight 52-60 g and body length $12-15 \mathrm{~cm}$ ) used for fast experiment were cultured in indoor tanks with circulating seawater at temperatures between 26 and $28^{\circ} \mathrm{C}$.

Fish were randomly divided into five groups (eight animals per group) for fasting experiments, and fed with commercial fish feed (YueQun Ocean Biological Research Development Company, Jieyang, China) once a day at $0900 \mathrm{~h}$. Fish were allowed to acclimate to the environment for 2 weeks. Two groups of fish were fed daily for 2 or 7 days while the remaining three groups were not fed. During the experiment, one fed group and one fasted group were sampled at 2 days. At the end of the 7 th day, one of the unfed groups was re-fed to satiety. Then the fed, fasted, and re-fed groups were sampled at $3 \mathrm{~h}$ after the scheduled feeding time at end of the experiment. The hypothalamus of each fish was removed and snap-frozen in liquid nitrogen.

To investigate the periprandial expression of $n m u$ and $n m s$ in the hypothalamus, fish were fed daily at a scheduled time $(0900 \mathrm{~h})$ for 4 weeks under the same conditions as described above. The daily scheduled feeding time was taken as time zero $(0 \mathrm{~h})$. The hypothalamuses were sampled at the following feeding times $(-3,0,1$, and $3 \mathrm{~h})$.

\section{The effects of $\mathbf{N m u}$ and $\mathbf{N m s}$ on the expression of appetite-related genes and the pituitary hormones}

Fish (body weight 750-800 g and body length $35-38 \mathrm{~cm}$ ) whose oocytes were in the stage of cortical alveolus

Published by Bioscientifica Ltd. 
were used for these experiments, being cultured in indoor tanks with circulating seawater at temperatures between 26 and $28^{\circ} \mathrm{C}$.

The test peptide was dissolved in $0.8 \%$ saline. Fish were anesthetized with $0.05 \%$ tricaine methanesulfonate and intraperitoneally injected with the test peptides: negative control fish were administered saline only, while experimental fish were injected with Nmu-21 and Nmsrp ( $250 \mathrm{ng} / \mathrm{g}$ body weight). The hypothalamus and pituitary were sampled at $6 \mathrm{~h}$ after the injection.

\section{Quantitative real-time PCR}

Quantitative real-time PCR was performed on a Roche LightCycler 480 Real-Time PCR System using SYBR Green Real-time PCR Master Mix (Toyobo) according to the manufacturer's protocol. The $10 \mu \mathrm{l}$ real-time PCRs contained $5 \mu \mathrm{l}$ SYBR Green Realtime PCR Master Mix, $0.5 \mu \mathrm{l}$ cDNA, $4.1 \mu \mathrm{l} \mathrm{H}_{2} \mathrm{O}, 0.2 \mu \mathrm{l}$ forward primer, and $0.2 \mu \mathrm{l}$ reverse primer. PCR conditions were as follows: denaturation at $94{ }^{\circ} \mathrm{C}$ for $2 \mathrm{~min}$, followed by 40 cycles at $94^{\circ} \mathrm{C}$ for $15 \mathrm{~s}, 55^{\circ} \mathrm{C}$ for $15 \mathrm{~s}$, and $72{ }^{\circ} \mathrm{C}$ for $20 \mathrm{~s}$. After amplification, a melting curve was obtained by reading the fluorescence value from 72 to $94^{\circ} \mathrm{C}$. The standard curve was generated between cycle threshold $\left(C_{\mathrm{t}}\right)$ value and the logarithm of vector dilutions using serial dilution of quantified pTZ57R vector (MBI Fermentas, Vilnius, Lithuania) containing the fragment of interest. The amplification efficiency of $n m u, n m s$, neuropeptide y (npy), orexin, proopiomelanocortin (pomc), corticotropin-releasing hormone (crh), follicle-stimulating hormone beta subunit $(f \operatorname{sh} \beta)$, LH beta subunit $(\operatorname{lh} \beta)$, thyroid-stimulating hormone beta subunit $(t s h)$, growth hormone $(g h)$, somatolaction ( $(s l)$, prolactin (prl), and $\beta$-actin genes was 83, 100, $97,83,83,91,92,85,91,91,100,89$, and $100 \%$ respectively. The concentration of the template in the sample was determined by relating the $C_{\mathrm{t}}$ value to the standard curve. Quantitative results were expressed as the ratio of target gene/ $\beta$-actin. The primers used in the study are listed in Supplementary Table 1.

\section{Statistical analyses}

All data are expressed as mean values \pm s.E.M. Statistical differences were assessed by using unpaired Student's $t$-test or a one-way ANOVA followed by a Duncan's multiple range test. $P$ value $<0.05$ was used as the definition of statistical significance. All analyses were performed using the SPSS Software 13.0 (SPSS).

\section{Results}

\section{Identification and synteny analysis of $\mathbf{n m u}$ and $\mathbf{n m s}$ in teleost fish}

A number of $n m u$ and $n m s$ candidates were found in the genomes of zebrafish, medaka, and Takifugu and in the EST database (Supplementary Information, see section on supplementary data given at the end of this article). To clarify the orthologous relationship of the predicted $n m u$ and $n m s$ sequences, we performed genomic synteny analyses: $n m u$ genes were found on the zebrafish chromosome 20 and on the Takifugu scaffold 13; nms genes were located on the zebrafish scaffold Zv9-NA923 and on the Takifugu scaffold 38. Gene clusters around the fish $n m u$ and nms homologs were determined and compared to those found around human and chicken NMU and NMS genes. As shown in Fig. 1, by comparing the NMU and NMS gene loci among these organisms, highly conserved synteny was observed. NMU is located in the genomic region that contains several common loci, including steroid 5 alpha-reductase 3 (SRD5A3), transmembrane protein 165 (TMEM165), and clock circadian regulator

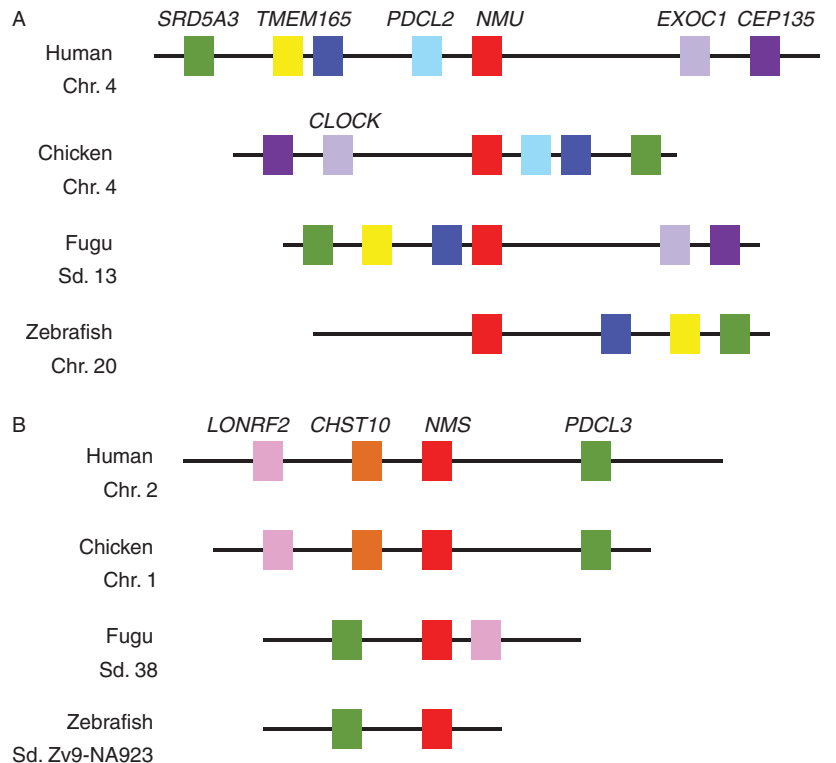

Figure 1

Genomic synteny analysis of (A) NMU and (B) NMS gene loci in the genome of several vertebrates. The chromosome or scaffold name of synteny blocks are shown on the left (Chr, chromosome; Sd, scaffold). Genes showing syntenic relationships are color-coded. SRD5A3, steroid 5 alpha-reductase 3; TMEM165, transmembrane protein 165; CLOCK, clock circadian regulator: $P D C L 2$, phosducin-like 2; EXOC1, exocyst complex component 1; CEP135, centrosomal protein $135 \mathrm{kDa}$; LONRF2, LON peptidase $\mathrm{N}$-terminal domain and ring finger 2; CHST10, carbohydrate sulfotransferase 10; PDCL3, phosducin-like 3 .

Published by Bioscientifica Ltd. 
(CLOCK). The neighboring genes around NMS, including phosducin-like 3 (PDCL3) and LON peptidase N-terminal domain and ring finger 2 (LONRF2), are conserved in zebrafish, Takifugu, chicken, and human.

\section{Cloning and sequence analysis of $n m u$ and $n m s$ CDNAs in the orange-spotted grouper}

Based on the known and predicted sequences, nmu and $n m s$ cDNA sequences were cloned from the brain of the orange-spotted groupers. The cloned $n m u$ cDNA fragment is $728 \mathrm{bp}$ in length with a $42 \mathrm{bp} 5^{\prime}$-UTR, a $257 \mathrm{bp} 3^{\prime}$-UTR, and a $429 \mathrm{bp}$ ORF. The Nmu precursor protein comprises 142 amino acids with a predicted signal peptide of 30 amino acids and a putative mature peptide of 21 amino acids (Fig. 2A). The cloned nms cDNA fragment is 1024 bp in length with a 204 bp 5'-UTR, a 457 bp 3'-UTR, and a $363 \mathrm{bp}$ ORF. The Nms precursor protein is composed of 120 amino acids with a predicted signal peptide of 26 amino acids and a putative mature peptide of 34 amino acids (Fig. 2B).

Sequence comparisons among the deduced amino acid sequences of the vertebrate NMU and NMS precursor proteins showed that the putative functional regions and some proteolytic cleavage site in these two precursor proteins are well conserved across vertebrates (Fig. 3). Interestingly, sequence comparison revealed that two putative peptides, the typical NMU peptides and a 33- or 32-amino acid peptide that we have named NMU-related peptide (NMURP), were found in mammals, chicken, goldfish, and zebrafish NMU precursor proteins. However, only the typical Nmu peptide containing 21 amino acids was observed in the orange-spotted grouper $\mathrm{Nmu}$ precursor protein (Fig. 3A). For NMS, two putative

A

43 ATGAGGACCGTCCAGAGCCAAAGTCAGCATGCGCAGCGCGGAGCCTCCAGCAGCCTGCACAGCCTCAGCAGCGGCGGCGTGAGTCCCCTC 132

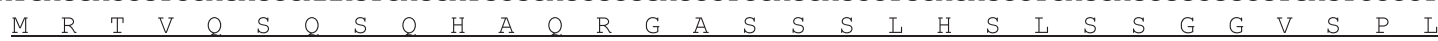

133 AGCACCACCAGCGTCACCCTCACAGCCCTGCTCATCATCCTCACCATCCCAGTCTGCCAAAGTGCTCCAGCAGAACTTCAGCAAGCCACA 222 $\begin{array}{lllllllllllllllllllllllllllllllllllllllll}S & T & T & S & V & T & L & T & A & L & L & I & I & L & T & I & P & V & C & Q & S & A & P & A & E & L & Q & Q & A & T\end{array}$

223 ACAGATCAGAGGCAGCTCCTCAGCCAGATAGACGCTGTGTGCTCATCCTACCTCTCTGCAGACCTGAAGTTTTGGGCATCTGATGTCTTA 312

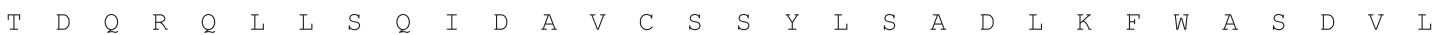

313 GGAGAACTCTGTGTCTTGATGCTGGTTCAGAAGTCAAAGGAGCTGAAAGTGCGAGAAAATAGTAAAAGGGCTGAACTCCAGGGACCTGGG 402

\begin{tabular}{lllllllllllllllllllllllll|llllllllll}
$G$ & $E$ & $L$ & $C$ & $V$ & $L$ & $M$ & $L$ & $V$ & $Q$ & $K$ & $S$ & $K$ & $E$ & $L$ & $K$ & $V$ & $R$ & $E$ & $N$ & $S$ & $\boldsymbol{K}$ & $\boldsymbol{R}$ & $\mathbf{A}$ & $\mathbf{E}$ & $\mathrm{L}$ & $\boldsymbol{Q}$ & $\mathrm{G}$ & $\mathbf{P}$ & $\mathrm{G}$
\end{tabular}

403 GGAATCCAGAGCAGAGGTTACTTCCTCTATCGGCCACGAAATGGAAGAAGATCCTTAGAATATGAGTAAATTAAAGAGTCGCCACCTCTG 492

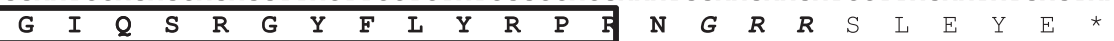

493 GAGCTGAGTGTACAGAGACAACACAGACCCTGAGACCCCGAGCCGCTGCACCACGACTGAGTGATCCAGACTTTAACCACAGTCCTTTGC 582 583 CACTGCTGTACAGTGATGTTTGAATGTACACAGAGAACATGATTAAAATACTCTCCATTTGTCCAGATTTTATTTTGTGTTATATGTGTG 672 673 TCATTTGCATTAAAACTGCAACAATGAAAAAAAAAAAAAAAAAAAAAAAAAAAAAA

\begin{tabular}{|c|c|c|}
\hline & ATGTCTGGGCCATTACGGCCGGGG & 24 \\
\hline 25 & GACACCTCACGGCTGTTAGACCAACCAGGAGAGCTGAGCTGAGCCAAGACACACCGAGACAAACTCAGTGGAACAGAGCTGAGCCACACC & 14 \\
\hline 5 & AAGTGGGCTGGTGTGGATCCACCAAGGAAGAACAACTCTCCAAACAAAGCGCACAGAGTTGAGTTGAGTGTAGGAGAGGAGAGAGGAGAC & \\
\hline & АTGTCTGTACCAACTGTGAGACAACTTTTTCTCCTGTGTTTCTTCTGGTGTCTGGGATCATGGAGCTCAGCAGATGCCAGTCCGTTTGAT & \\
\hline & $\begin{array}{llllllllllllllllllllllllllllll}M & S & V & P & T & V & R & Q & L & F & L & L & C & F & F & W & C & L & G & S & W & S & S & A & D & A & S & P & F & D\end{array}$ & \\
\hline & CAGTGGGAGGACGGGATCCAGTTAAGGAAGGTGCGAGGCGTCCAGAGTGATGACCTGAGTGATGCATTGTGGGAGGATCAGAAGGAGGAG & 34 \\
\hline & 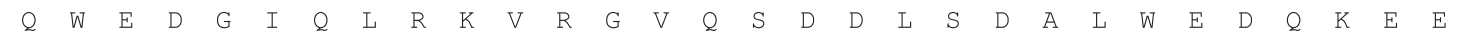 & \\
\hline & САGAACGTCTTCAAAAGATTCCTGTTTCATTACTCTAAAGCACGAAACTCAGTAGGAGCCGTGCAGCAGGAGTCTCACTCAGTC & 474 \\
\hline & $\begin{array}{lllllllllllllllllllllllllll}Q & \mathrm{~V} & \mathrm{Q} & \mathrm{N} & \mathrm{V} & \mathrm{F} & \boldsymbol{K} & \boldsymbol{R} & \mathbf{F} & \mathrm{L} & \mathbf{F} & \mathrm{H} & \mathbf{Y} & \mathbf{S} & \mathbf{K} & \mathbf{A} & \mathbf{R} & \mathbf{N} & \mathbf{S} & \mathbf{V} & \mathbf{G} & \mathbf{A} & \mathbf{V} & \mathbf{Q} & \mathbf{Q} & \mathbf{E} & \mathbf{S} \\
\end{array}$ & \\
\hline & САTССTCTGATGAGACTTTCTCCCAAACTATCCCAGAGGAGAAAGAAGAAGGTTTTACTGTTGATTCGCGGTCTGCCTGAGGGGATGTTG & 564 \\
\hline & \begin{tabular}{llllllll|llllllllllllllllll}
$\mathbf{R}$ & $\mathrm{L}$ & $\mathbf{S}$ & $\mathbf{P}$ & $\mathrm{K}$ & $\mathrm{L}$ & $\mathbf{S}$ & $\mathbf{Q}$ & $\boldsymbol{R}$ & $\boldsymbol{R}$ & $\mathrm{K}$ & $\mathrm{K}$ & $\mathrm{K}$ & $\mathrm{V}$ & $\mathrm{L}$ & $\mathrm{L}$ & $\mathrm{L}$ & $\mathrm{I}$ & $\mathrm{R}$ & $\mathrm{G}$ & $\mathrm{L}$ & $\mathrm{P}$ & $\mathrm{E}$ & $\mathrm{G}$ & $\mathrm{M}$ & $\mathrm{L}$
\end{tabular} & \\
\hline & $\begin{array}{l}\text { TAGAAGAATCGACCACAAGAGACAGACGTCAAGCTGAAGAGAAGAGGAGCAGCAGGCAGCACCTGAACGTCACCATCACTGAGCCGAGGA } \\
\text { * }\end{array}$ & 654 \\
\hline & GCCATGTTCAGACACACACACACACACACACACACACACACACACACACACACAGGACCTTTTTTTATGAGAAAATAAATCATTGTACAG & 744 \\
\hline & ATGGAGACAGCAGAACCACTCCAACATGGCTGCCATGTGTCTTCCTGCTTCCACGTCAATCAGTGTACGTCAGTGTGAACTGTTGTTTTG & 834 \\
\hline & TTACACAAGACACAAGCGTCACCAAATACACACCAAACACATTCATTTTTTAAACAAGTTCTTTATGATTCCAGAACACAGATTAACATG & 924 \\
\hline & GCATCGAGGTGAACTCACATTTGATTCAACAGATTTACAGTTTGTGACATCATGAAATAAAAAAGTTAAACTCAAAAAAAAAAAAAAAAA & 1014 \\
\hline & AAAAAAAAA & 1024 \\
\hline
\end{tabular}

Figure 2

Nucleotide sequences and the deduced amino acid sequences of the orange-spotted grouper $\mathrm{Nmu}$ (A) and $\mathrm{Nms}$ (B). The putative signal peptides
(C) 2015 Society for Endocrinology Printed in Great Britain are underlined. The mature peptides are boxed and shown in bold. The proteolytic cleavage sites are italic and shown in bold. 
A

Human NMU Mouse NMU Goldfish Nmu Zebrafish Nmu Grouper Nmu

Human NMU Mouse NMU Goldfish Nmu Zebrafish Nmu Grouper Nmu

Human NMU Mouse NMU Goldfish NMU Zebrafish NMU Grouper NMU

\section{B}

Human NMS Mouse NMS Grouper Nms Medaka Nms Zebrafish Nms

Human NMS Mouse NMS Grouper Nms Medaka Nms Zebrafish Nms

Human NMS Mouse NMS Grouper Nms Medaka Nms Zebrafish Nms

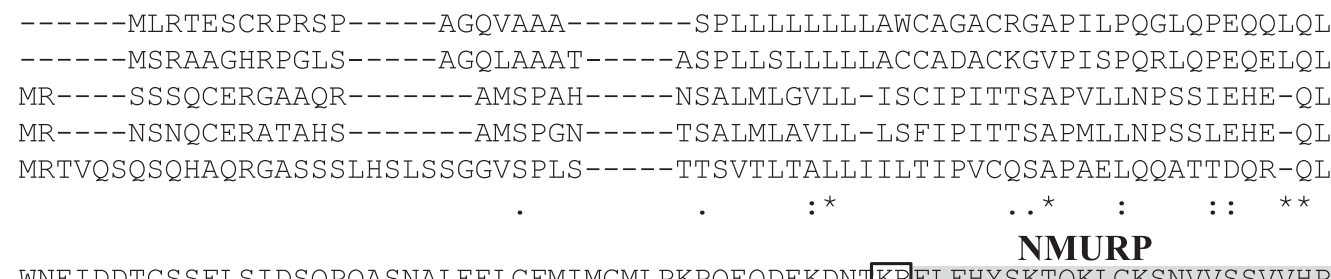

WNEIDDTCSSFLSIDSQPQASNALEELCFMIMGMLPKPQEQDEKDNTKRFLFHYSKTQKLGKSNVVSSVVHP WNEIHEACASFLS IDSRPQASVALRELCRIVME ISQKPQEQSEKDNTKR FLFHYSKTQKLGNSNVVSSVVHP LTQITDLCSFYLSADPSFRTSDVLEDLCFLMLGSLQKSKEITARETAKRFLFHYTKPNGAGLSDGTSTVLHP LTQITDLCSFYLSADPSFRTSDVLEDLCFLMLGSLQKSKEITARETSKRFLFHYTKPNGAGLSDGTSTVLHP

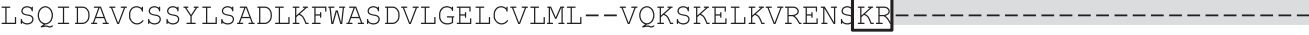

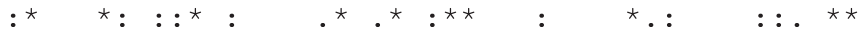

\section{NMU}

LLQLVPHLHERRMKRRVDEEFQSPFASQSRGYFLFRPRNGRASAGFI

LLQLVPQLHERRMKAFKA--EYQSPSVGQSKGYFLFRPRNGKASTSF I

LLELIPHLA RRRARAMKLNDDLQGPGRIQSRGFFLYRPRNARASDEYV

LLEL I PQLA RR RSRAMKLNENLQGPGRIQSRGYFLYRPRNGRA SDEYV

-AELQGPGGIQSRGYFLYRPRNCRBSLEY-

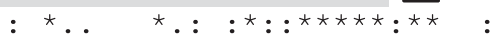

MKHLRPQFPLILA IYCFCMLQI PSSGFPQPLADPSDG--LDIVQLEQLAY-CLSQWAPLSRQPKDNQDI MKHPLPHYSPILFIYCFCMLQIPSSGASPPLADSPDG--LDIVDPERLAY-FLKQREIHSNQPKENQDV --MSVPTVRQLFLLCFFWCLGSWSSADASPFDQWEDG--IQLRKVRGVQSDDLSDALWEDQKEEQVQNV ----MTGVRQVFLLFLFGFLWYRRTTEASLFDQWEDG--TALQKVRGIRSDDLSNVLWRDQNEEQVQNI ----MGFSAICCLLWF ISCFYSAVESFPSPLTDCDDNDS SDY IQGSAVLS-SLCALQWRDQEQEHIQNV

\section{NMSRP NMS}

YKRFLFHYSRTQEATHPVKTGFPPVHPLMHLAAKLANRRMK---RILQRGSGTAAVDFTKKDHTATWGR YKR FLFHYSRTRKPTHPVSAEFAPVHPLMRLAAKLASRRMKRLPRLLRLDSRMATVDFPKKDPTTSLGR F KRFLFHYSKARNSVGAVQQES HSVHPLMRLSPKLSORRKKKVLLLKIRGLPEGML------- - - F KR FLFHYSKARNSLGAVQQESHSVHPLMRLSPKLSORRKKKVVLLKIRGLPEGMLQ---- - - - - EKRFLFHYSKAQNSLGSVERESHSVHPLMRLSPRLSIRRKKQ-- - QQRS - - - - - - - - - - - - - - -

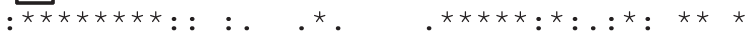

PEFLFRPRNGRNIEDEAQIQW PEFLFRPRNABYTDNNFQ---
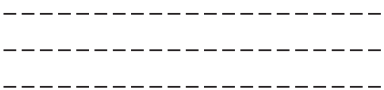

\section{Figure 3}

Comparison of amino acid sequences of fish and mammalian NMU (A) and NMS (B). The putative peptides are shaded in grey and proteolytic cleavage sites are boxed.

peptides, the typical NMS peptides and a 34-amino acid peptide that we have named NMSRP, were also found in the mammalian NMS precursor proteins. However, the typical mature Nms peptide was lost in the teleostean Nms precursor proteins, and only the Nmsrp was retained (Fig. 3B).

Phylogenetic analysis showed that NMU and NMS sequences are clustered into two separate clades, with NMU in one clade and NMS in the other (Fig. 4).

\section{Tissue distribution of $n m u$ and $n m s$ mRNA in the orange-spotted grouper and their localization in the brain}

RT-PCR analysis was performed to examine the tissue expression patterns of $n m u$ and $n m s$ genes. As shown in Fig. 5, $n m u$ is expressed in brain, pituitary, stomach, muscle, kidney, spleen, gill, heart, and ovary tissues, while $n m s$ can be observed in almost all tissues examined except the heart.

In situ hybridization studies revealed that $n m u$ - and nms-expressing cells are mainly localized in the

Published by Bioscientifica Ltd 


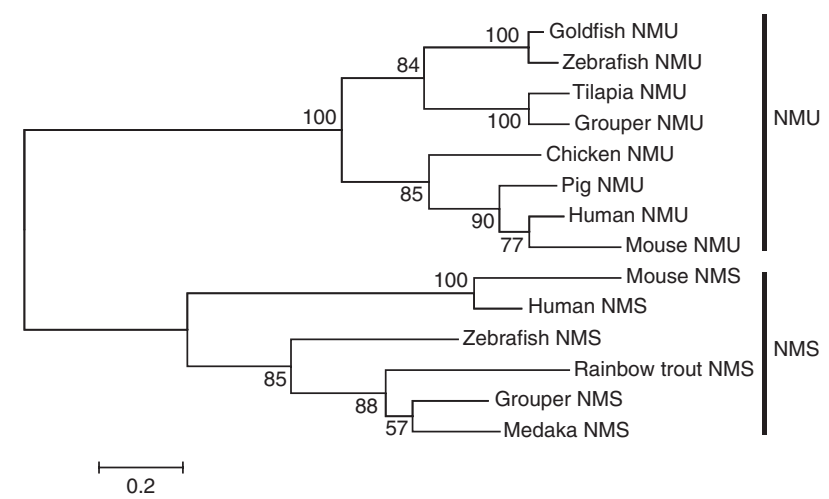

Figure 4

Phylogenetic analysis of NMU and NMS in vertebrates. The phylogenetic tree was constructed using MEGA 3.1 and the neighbor-joining method. Data were re-sampled by 1000 bootstrap replicates. The sequences and their accession numbers are: human NMU (NP_006672.1), mouse NMU (NP_062388.1), pig NMU (XP_003129080.1), chicken NMU (XP_420701.1), goldfish NMU (BAH57726), zebrafish NMU (NP_001292548), tilapia NMU (XP_003439981.1), human NMS (NP_001011717.1), mouse NMS (NP_001011684.3), zebrafish NMS (XP_003201803.1), rainbow trout NMS (BX297606.3), and medaka NMS (AM146637.1).

hypothalamus of the orange-spotted grouper (Fig. 6). $n m u$ signals were strongly found in the lateral tuberal nucleus, ventral part (NLTv), while nms-positive cells were found in the ventral zone of the periventricular hypothalamus (Hv). No staining was detected using the sense riboprobes of $n m u$ and $n m s$ (data not shown). The neuroanatomy in this study was identified by using the orange-spotted grouper atlas (Nagarajan et al. 2013).

\section{Changes of hypothalamic $n m u$ and $n m s$ mRNA levels under different feeding regimes}

Real-time PCR was used to study $n m u$ and $n m s$ mRNA levels under different feeding regimes. As shown in Fig. 7A, there was no significant change in $n m u$ mRNA levels in hypothalamus after 2 days of food deprivation, but a significant increase of hypothalamic $n m s$ mRNA levels was observed. Seven days of food deprivation induced a significant reduction in $n m u$ mRNA levels in the hypothalamus, but its expression was markedly increased in the 7-day fasted fish after re-feeding. However, there was no significant change in the $n m s$ mRNA levels in the hypothalamus after 7 days of food deprivation and re-feeding (Fig. 7A).

Periprandial changes in $n m u$ and $n m s$ mRNA levels in the hypothalamus of the orange-spotted grouper are shown in Fig. 7B. The hypothalamic expression of $n m u$ did not change at $3 \mathrm{~h}$ before feeding and at 0 and $1 \mathrm{~h}$ after feeding. However, there was a significant increase in $n m u$ expression at $3 \mathrm{~h}$ post-feeding compared to that at other time point. The hypothalamic expression of $n m s$ was elevated at the normal feeding time $(0 \mathrm{~h})$, and then dropped to pre-feeding level at 1 and $3 \mathrm{~h}$ post-feeding.

\section{Expression of appetite-related genes in the hypothalamus after the Nmu-21 and Nmsrp administration}

The effects of Nmu-21 and Nmsrp administration on the expression of appetite-related genes, $n p y, p o m c, c r h$, and orexin, were investigated in the orange-spotted grouper. As shown in Fig. 8, peripheral administration of grouper Nmu-21 peptide slightly suppressed the expression of hypothalamic $n p y$, but had no effect on the hypothalamic expression of orexin, pomc, and crh. Grouper Nmsrp significantly stimulated the expression of npy and orexin in the hypothalamus, but could not change the hypothalamic expression of pomc and crh (Fig. 8).

\section{The effects of Nmu-21 and Nmsrp on the mRNA levels of pituitary hormones}

The effects of Nmu-21 and Nmsrp administration on the expression of pituitary hormones, including $f \operatorname{sh} \beta, \operatorname{lh} \beta, t \operatorname{sh} \beta$, $g h, p r l$, and $s l$, were investigated in the orange-spotted grouper. As shown in Fig. 9, the mRNA levels of $\operatorname{lh} \beta$ and $g h$ in pituitary of the orange-spotted grouper were significantly down-regulated after peripheral injection of Nmu-21 peptide. There was no obvious effect of Nmu-21 peptide on the expression of other pituitary hormones. On the other hand, Nmsrp could significantly up-regulate the mRNA levels of $f \operatorname{sh} \beta, p r l$, and $s l$ but showed no effect on the expression of $\operatorname{lh} \beta, \operatorname{tsh} \beta$, and $g h$ in the pituitary.

\section{Discussion}

In the present study, we have identified nmu and $n m s$ in several fish species and have cloned the cDNAs of these

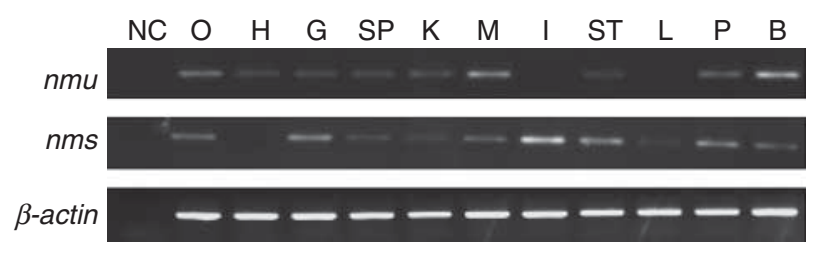

\section{Figure 5}

RT-PCR analysis of tissue expression patterns of $n m u$ and $n m s$ in the orangespotted grouper. Amplification of $\beta$-actin was used as the housekeeping gene control. B, brain; P, pituitary; L, liver; ST, stomach; I, intestine; M, muscle; K, kidney; SP, spleen; G, gill; H, heart; O, ovary; NC, negative control.

Published by Bioscientifica Ltd. 
A

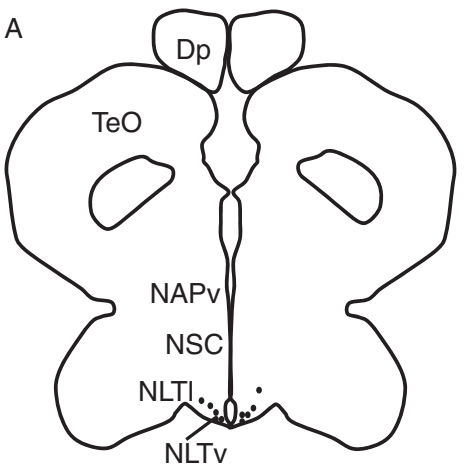

B

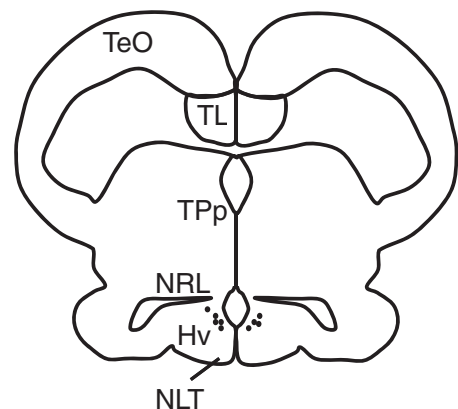

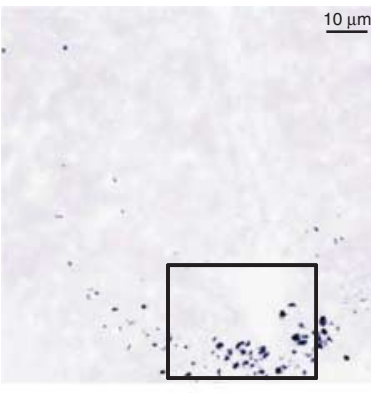

$0 \mu \mathrm{m}$

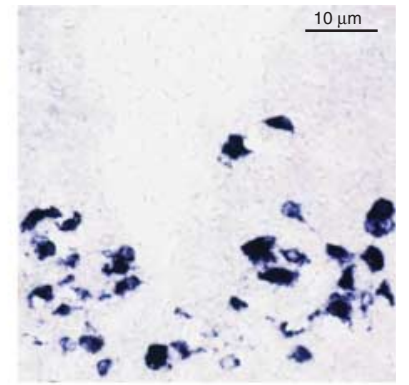

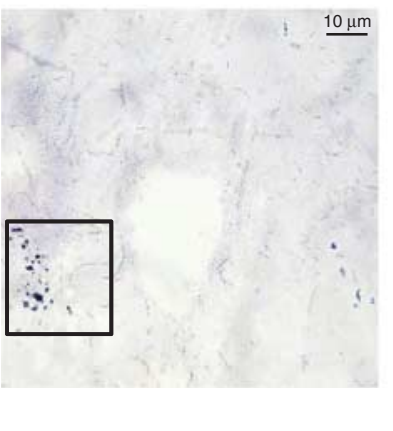

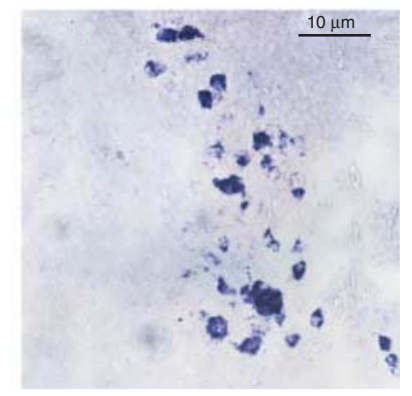

\section{Figure 6}

Localization of $n m u(A)$ and $n m s(B)$ mRNA-expressing cells in the brain of the orange-spotted grouper. $\mathrm{Dp}$, dorsal posterior thalamic nucleus; $\mathrm{Hv}$, ventral zone of the periventricular hypothalamus; NAPv, anterior periventricular nucleus; NLT, lateral tuberal nucleus; NLTI, lateral tuberal

two genes from the orange-spotted grouper. Some differences were found in the precursors of $\mathrm{Nmu}$ and $\mathrm{Nms}$ between fish species, as well as between fish and other vertebrates. For example, two putative peptides are present in the precursor of NMU in other vertebrates and in some fish species such as common carp and goldfish. But Nmurp nucleus, lateral part; NLTv, lateral tuberal nucleus, ventral part; $N R L$, nucleus of the lateral recess; NSC, suprachiamatic nucleus; $\mathrm{TeO}$, tectum opticum; TL, torus longitudinalis; TPp, periventricular nucleus of the posterior tuberculum.

could not be found in the present cloned sequence of orange-spotted grouper. Studies in mammals, common carp and goldfish have shown that nmu genes could produce several alternative splicing variants during transcription (Chen et al. 2006, Maruyama et al. 2008, Kono et al. 2012). It was found that the nucleotide sequences
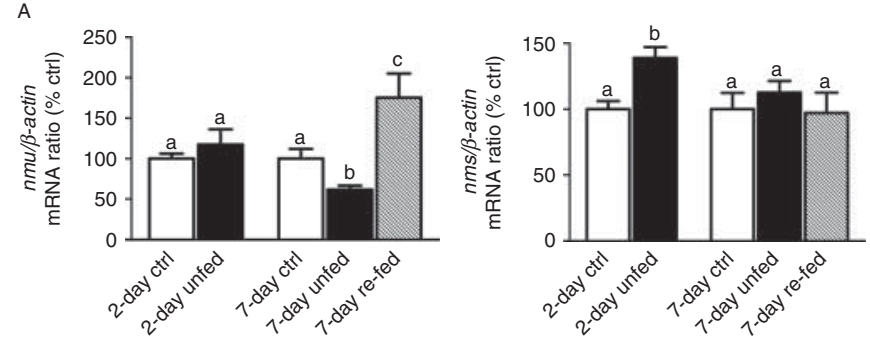

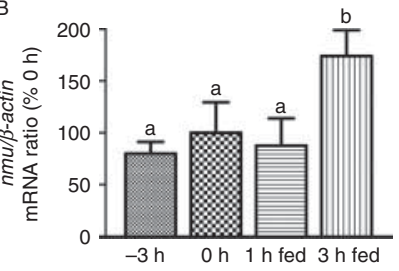

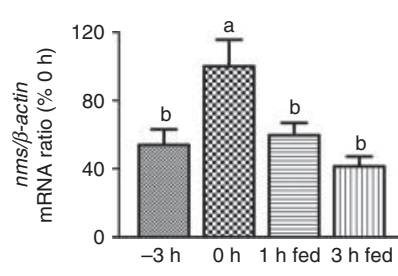

Figure 7

mRNA expression of $n m u$ and $n m s$ under different feeding regimes. (A) Relative mRNA levels of $n m u$ and $n m s$ in the hypothalamus of orangespotted grouper after 2- and 7-day fasting. Re-feeding was introduced at 7 days after food deprivation. The data obtained at different groups were normalized as \% 2-day ctrl or 7-day ctrl. $P<0.05$ vs the corresponding control (unpaired Student's $t$-test or one-way ANOVA with the Duncan's multiple
(C) 2015 Society for Endocrinology Printed in Great Britain range tests). (B) Periprandial changes of $n m u$ and $n m s$ in the hypothalamus of orange-spotted grouper. Fish food was introduced at $0900 \mathrm{~h}$ (taken as time zero, $0 \mathrm{~h}$ ). The data obtained at different groups were normalized as $\% \mathrm{ctrl}$ at time $0 \mathrm{~h}$. Values are expressed as mean \pm S.E.M. ( $n=8$ for each group). $P<0.05$ vs the group at time $0 \mathrm{~h}$ (one-way ANOVA with the Duncan's multiple range tests). Different letters denote statistically significant differences.

Published by Bioscientifica Ltd. 

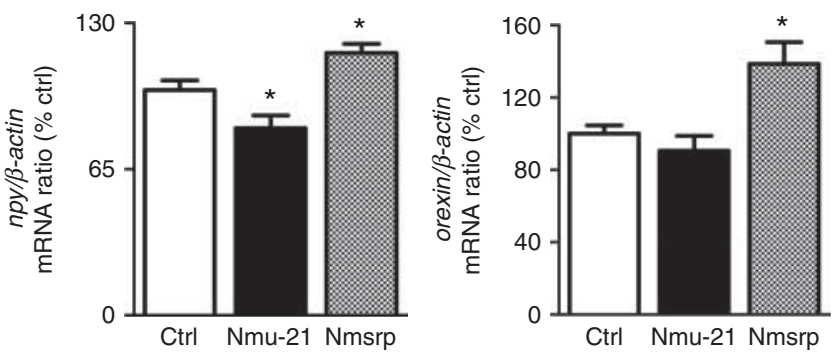

Figure 8

In vivo effects of Nmu-21 and Nmsrp on the expression of appetite-related genes in the hypothalamus of orange-spotted grouper. Fish were injected intraperitoneally with Nmu-21 and Nmsrp at a dose of $250 \mathrm{ng} / \mathrm{g}$ bodyweight. Hypothalamus samples were collected at $6 \mathrm{~h}$ post-injection.

encoding Nmurp were absent in some cDNA variants in goldfish and common carp as well (Maruyama et al. 2008, Kono et al. 2012). Whether the loss of Nmurp in orangespotted grouper is caused by alternative splicing regulation is uncertain, as we did not successfully isolate other cDNA variants in this study. It was observed that $n m u$ variants exhibited organ-specific expression in the goldfish. Although four cDNAs encoding $n m u$ were identified in goldfish, only one splice variant, which did not contain Nmurp and also encodes a putative 21 amino acids $\mathrm{Nmu}$ peptide, was highly expressed in the brain and its expression was reduced by fasting (Maruyama et al. 2008). The aim of this study was to investigate the role of $n m u$ in the regulation of feeding and energy balance. Therefore, the cloned cDNA from the brain of orangespotted grouper is suitable for our subsequent analysis.

As for the Nms precursor protein, it is likely that the typical Nms peptide was lost in the teleost fish during evolution. We searched the sequence of $n m s$ gene in the genome databases and EST database. Some transcript variants were predicted in fish, but no typical Nms peptide was found in the precursors of these variants either (Supplementary Information). Moreover, the nucleotide sequence corresponding to Nms peptide could not be found in the genomes of any of fish species analyzed here. Although the existence of NMSRP protein in vertebrates remains to be confirmed, according to the potential protease cleavage sites, it has been proposed that NMURP and NMSRP may be generated from their proproteins (Austin et al. 1995). One report mentioned that an endogenous 33-residue peptide NMURP had been purified from rat brain and small intestine extracts, and found that both synthetic NMURP and NMSRP showed potent PRL-releasing activity in rats (Mori et al. 2005). In another study, synthetic NMURP was found to
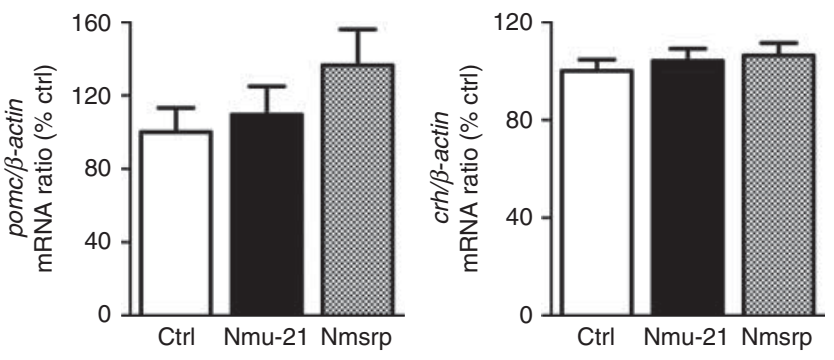

The data obtained at different groups were normalized as \% ctrl without peptide treatment. Values are expressed as mean values \pm s.E.M. $(n=6-8)$. $\star P<0.05$ vs the corresponding control.

significantly induce feeding behavior, body weight, and metabolic rate in mice (Bechtold et al. 2009). These data imply that the NMURP and NMSRP in vertebrates possess biological functions.
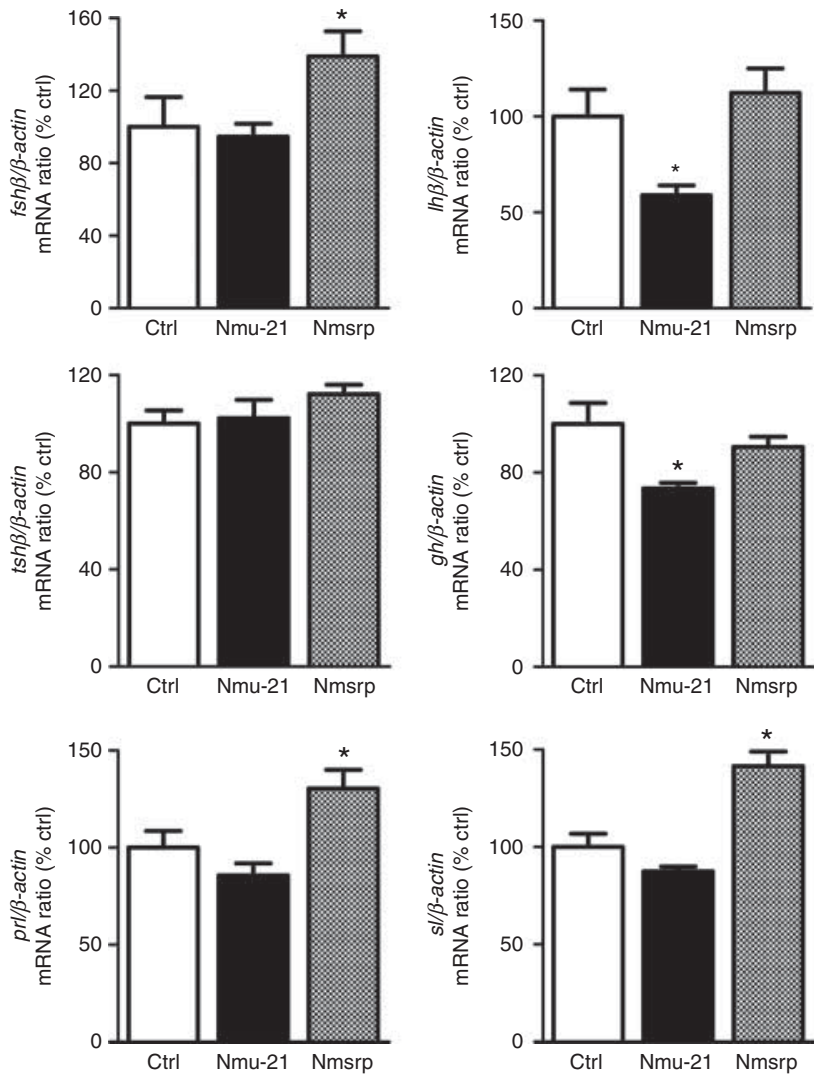

\section{Figure 9}

In vivo effects of Nmu-21 and Nmsrp on the expression of the pituitary hormones in the orange-spotted grouper. Pituitaries were collected at $6 \mathrm{~h}$ post-injection. The data obtained at different groups were normalized as \% ctrl without peptide treatment. Values are expressed as mean values \pm S.E.M. $(n=6-8) .{ }^{*} P<0.05$ vs the corresponding control. 
RT-PCR showed that $n m u$ and $n m s$ are broadly expressed in brain and peripheral tissues in the orangespotted grouper, in a manner similar to that observed in goldfish (Maruyama et al. 2008). Brain is the key organ in which NMU and NMS exert their functions. In situ hybridization analysis in the orange-spotted grouper revealed that $n m u$-expressing cells are abundant in the NLT of the hypothalamus, while the cells expressing $n m s$ are located in the Hv. The NLT and Hv may be associated with feeding control in fish as well. Studies have demonstrated that several important neuropeptides associated with food intake are expressed in the NLT and Hv, including $n p y$, pomc, mch, and crh (Castro et al. 1999, Cerdá-Reverter et al. 2000, 2003, Pepels et al. 2002, Alderman \& Bernier 2007, Amano et al. 2009, Berman et al. 2009). Although we do not know whether these genes are also localized in the NLT and Hv in the orange-spotted grouper, studies in other fish species have demonstrated that the functions and localizations of these peptides in the brain are well conserved (reviewed by Lin et al. (2000), Volkoff et al. (2005) and Matsuda et al. (2012)). Thus, nmu and $n m s$ are highly likely to play roles in feeding regulation and energy homeostasis in the orange-spotted grouper, and are implicated in interaction with the appetite-related genes.

In agreement with our assumptions above, nmu and $n m s$ gene expression was regulated by changes in energy balance. nmu expression was reduced after a 7-day period of food deprivation and increased dramatically after feeding in orange-spotted grouper. This result is in accordance with those found in rodents and goldfish (Howard et al. 2000, Ivanov et al. 2002, Maruyama et al. 2008), indicating that the anorexic roles of $n m u$ are evolutionarily conserved from fish to mammals. The present study of the periprandial expression of $n m u$ also provided evidence for anorexic roles in the orange-spotted grouper, as nmu mRNA levels were significantly elevated at $3 \mathrm{~h}$ after the normal feeding. There is a similar report of $n m u$ expression increasing under positive energy balance in rodents. $n m u$ mRNA levels were elevated in the dorsomedial hypothalamic nucleus of obese $o b / o b$ mice compared to lean litter-mates (Graham et al. 2003). A number of studies have demonstrated that $n m s$ acts as an anorexigenic factor (reviewed by Novak (2009)). Unexpectedly, in the orange-spotted grouper, nms expression was up-regulated by 2-day fasting and $n m s$ mRNA levels had gone up at the start of normal feeding. These expression patterns are similar to that of the orexingenic gene npy and orexin in orange-spotted grouper. Previous studies showed that the expression of npy and orexin were dramatically increased at the time of feeding and after the food deprivation (Yan et al. 2011, Tang et al. 2013). These data suggest that the nms gene may play an orexigenic role in the orange-spotted grouper.

In mammals, the anorexigenic actions of NMU and NMS are mediated by the activation of CRH neurons (reviewed by Malendowicz et al. (2012)). Administration of NMU could not suppress food intake or increase oxygen consumption and body temperature in CRH-knockout mice (Hanada et al. 2003). Administration of NMS could upregulate the $C R H$ mRNA levels in the brain, and the NMS-mediated inhibition of food intake could be attenuated by pretreatment with the antagonist of CRH (Ida et al. 2005, Nakahara et al. 2010). In goldfish, a significant increase in the expression of $c r h$ mRNA was observed after injection with Nmu-21 peptide, and the anorexigenic effect of this peptide was erased by treatment with the antagonist of Crh receptor (Maruyama et al. 2008). However, this pathway appears to be not conserved in the orange-spotted grouper. Peripheral administration of Nmu-21 peptide had little effect on the crh mRNA levels, but slightly suppressed the expression of the orexingenic gene npy in hypothalamus of the orange-spotted grouper. Additionally, Nmu-21 peptide could not change the mRNA levels of other feeding-related factors such as orexin and pomc. These data suggest that the anorexigenic action of Nmu might be mediated by the suppression of Npy or other unknown factors in the orange-spotted grouper. On the other hand, Nmsrp could significantly increase the mRNA levels of npy and orexin, corresponding well to its putative orexigenic role in the orange-spotted grouper. Although there is limited information about the exact biological functions of NMSRP, a study have found that a significant but transient increase in feeding was observed in mice after central administration of NMURP (Bechtold et al. 2009). In vertebrates, NMSRP shares relative high sequence similarity to the NMURP, implying its involvement in the regulation of energy balance. Taken together, it appears that the fish nms shows an opposite function to its mammalian counterparts. The structural discrepancy may be responsible for the functional difference of NMS genes between fish and mammals. Nevertheless, its roles in regulating the feeding behavior of the orange-spotted grouper need further confirmation.

Additionally, Nmu-21 peptide and Nmsrp were found to have effects on the expression of some pituitary hormones in the orange-spotted grouper. Nmu-21 inhibited the $\ln \beta$ transcript expression but Nmsrp elevated the $f s h \beta$ mRNA levels, suggesting that these peptides are involved in the regulation of the gonadotropic axis in the

Published by Bioscientifica Ltd 
orange-spotted grouper. Our data also further confirm the negative role of NMU in vertebrate reproduction, and first disclose the potential involvement of $n m s$ in the regulation of $f$ sh expression. Furthermore, Nmu-21 peptide was found to suppress gh expression, and Nmsrp stimulated prl and $s l$ expression. These data suggest that nmu and nms may possess pituitary functions in the orange-spotted grouper, and also provide some indications for further study on the function of NMSRP in vertebrates.

In summary, we have identified the $n m u$ and $n m s$ genes in fish species. And for the first time we have simultaneously characterized the putative roles of $n m u$ and $n m s$ in a single species, the orange-spotted grouper, in terms of their sequence analysis, localization analysis, expression profiles under different energy statuses, interaction with feeding related factors and the regulation on pituitary hormones. Our study is highly suggestive of distinct roles for $n m u$ and $n m s$ genes in regulation feeding and of possessing different pituitary functions in the orangespotted grouper, paving the way for further evaluation of their physiological significance in fish species.

\section{Supplementary data}

This is linked to the online version of the paper at http://dx.doi.org/10.1530/ JME-15-0018.

\section{Declaration of interest}

The authors declare that there is no conflict of interest that could be perceived as prejudicing the impartiality of the research reported.

\section{Funding}

This study was supported by the National '863' Program of China (2012AA10A407), the National Natural Science Foundation of China (31261160493), the Special Fund for Fisheries-Scientific Research of Guangdong Province (A201400A01, A201501A03 and A201501A09), the Project of Science and Technology New Star in Zhujiang city (2013J2200093), the Fundamental Research Funds for the Central Universities (151gzs102 and 151gzs121), and the Hainan Province Marine Science and technology foundation (XH201401).

\section{References}

Alderman SL \& Bernier NJ 2007 Localization of corticotropin-releasing factor, urotensin I, and CRF-binding protein gene expression in the brain of the zebrafish, Danio rerio. Journal of Comparative Neurology $\mathbf{5 0 2}$ 783-793. (doi:10.1002/cne.21332)

Amano M, Amiya N, Hiramatsu M, Tomioka T \& Oka Y 2009 Interaction between neuropeptide $\mathrm{Y}$ immunoreactive neurons and galanin immunoreactive neurons in the brain of the masu salmon, Oncorhynchus masou. Neuroscience Letters 462 33-38. (doi:10.1016/ j.neulet.2009.06.067)
Austin C, Lo G, Nandha KA, Meleagros L \& Bloom SR 1995 Cloning and characterization of the cDNA encoding the human neuromedin U (NMU) precursor-NMU expression in the human gastrointestinal tract. Journal of Molecular Endocrinology 14 157-169. (doi:10.1677/jme.0.0140157)

Bechtold DA, Ivanov TR \& Luckman SM 2009 Appetite-modifying actions of pro-neuromedin U-derived peptides. American Journal of Physiology. Endocrinology and Metabolism 297 E545-E551. (doi:10.1152/ajpendo. 00255.2009)

Bendtsen JD, Nielsen H, Heijne GV \& Brunak S 2004 Improved prediction of signal peptides: SignalP 3.0. Journal of Molecular Biology 340 783-795. (doi:10.1016/j.jmb.2004.05.028)

Berman JR, Skariah G, Maro GS, Mignot E \& Mourrain P 2009 Characterization of two melanin-concentrating hormone genes in zebrafish reveals evolutionary and physiological links with the mammalian MCH system. Journal of Comparative Neurology $\mathbf{5 1 7}$ 695-710. (doi:10.1002/cne.22171)

Budhiraja S \& Chugh A 2009 Neuromedin U: physiology, pharmacology and therapeutic potential. Fundamental \& Clinical Pharmacology 23 149-157. (doi:10.1111/j.1472-8206.2009.00667.x)

Castro A, Becerra M, Manso MJ \& Anadón R 1999 Development of immunoreactivity to neuropeptide $\mathrm{Y}$ in the brain of brown trout (Salmo trutta fario). Journal of Comparative Neurology 414 13-32. (doi:10.1002/ (SICI)1096-9861(19991108)414:1 < 13::AID-CNE2>3.0.CO;2-R)

Cerdá-Reverter JM, Anglade I, Martínez-Rodríguez G, Mazurais D, MuñozCueto JA, Carrillo M, Kah O \& Zanuy S 2000 Characterization of neuropeptide Y expression in the brain of a perciform fish, the sea bass (Dicentrarchus labrax). Journal of Chemical Neuroanatomy 19 197-210. (doi:10.1016/S0891-0618(00)00063-6)

Cerdá-Reverter JM, Schioth HB \& Peter RE 2003 The central melanocortin system regulates food intake in goldfish. Regulatory Peptides 115 101-113. (doi:10.1016/S0167-0115(03)00144-7)

Chen TB, Zhou M, Walker B, Harriot P, Mori K, Miyazato M, Kangawa K \& Shaw C 2006 Structural and functional analogs of the novel mammalian neuropeptide, neuromedin S (NMS), in the dermal venoms of Eurasian bombinid toads. Biochemical and Biophysical Research Communications 345 377-384. (doi:10.1016/j.bbrc.2006.04.103)

Fujii R, Hosoya M, Fukusumi S, Kawamata Y, Habata Y, Hinuma S, Onda H, Nishimura O \& Fujino M 2000 Identification of neuromedin $U$ as the cognate ligand of the orphan G protein-coupled receptor FM-3. Journal of Biological Chemistry 275 21068-21074. (doi:10.1074/ jbc.M001546200)

Graham ES, Turnbull Y, Fotheringham P, Nilaweera K, Mercer JG, Morgan PJ \& Barrett P 2003 Neuromedin U and neuromedin U receptor-2 expression in the mouse and rat hypothalamus: effects of nutritional status. Journal of Neurochemistry 87 1165-1173. (doi:10.1046/ j.1471-4159.2003.02079.x)

Hanada T, Date Y, Shimbara T, Sakihara S, Murakami N, Hayashi Y, Kanai Y, Suda T, Kangawa K \& Nakazato M 2003 Central actions of neuromedin U via corticotropin-releasing hormone. Biochemical and Biophysical Research Communications 311 954-958. (doi:10.1016/j.bbrc.2003.10.098)

Hanada R, Teranishi H, Pearson JT, Kurokawa M, Hosoda H, Fukushima N, Fukue Y, Serino R, Fujihara H, Ueta Y et al. 2004 Neuromedin U has a novel anorexigenic effect independent of the leptin signaling pathway. Nature Medicine 10 1067-1073. (doi:10.1038/nm1106)

Howard AD, Wang R, Ponget SS, Mellin TN, Strack A, Guan XM, Zeng Z, Williams DL Jr, Feighner SD, Nunes CN et al. 2000 Identification of receptors for neuromedin $\mathrm{U}$ and its role in feeding. Nature 406 70-74. (doi:10.1038/35017610)

Ida T, Mori K, Miyazato M, Egi Y, Abe S, Nakahara K, Nishihara M, Kangawa K \& Murakami N 2005 Neuromedin s is a novel anorexigenic hormone. Endocrinology 146 4217-4223. (doi:10.1210/en.2005-0107)

Ivanov TR, Lawrence CB, Stanley PJ \& Luckman SM 2002 Evaluation of neuromedin $\mathrm{U}$ actions in energy homeostasis and pituitary function. Endocrinology 143 3813-3821. (doi:10.1210/en.2002-220121)

Kono T, Hamasuna S, Korenaga H, Iizasa T, Nagamine R, Ida T \& Sakai M 2012 The role of neuromedin $U$ during inflammatory response in the

Published by Bioscientifica Ltd. 
common carp. Fish \& Shellfish Immunology 32 151-160. (doi:10.1016/ j.fsi.2011.11.004)

Kowalski TJ, Spar BD, Markowitz L, Maguire M, Golovko A, Yang S, Farley C, Cook JA, Tetzloff G, Hoos L et al. 2005 Transgenic overexpression of neuromedin $\mathrm{U}$ promotes leanness and hypophagia in mice. Journal of Endocrinology 185 151-164. (doi:10.1677/joe.1.05948)

Kumar S, Tamura K \& Nei M 2004 MEGA3: integrated software for molecular evolutionary genetics analysis and sequence alignment. Briefings in Bioinformatics 5 150-163. (doi:10.1093/bib/5.2.150)

Lin XW, Volkoff H, Narnaware Y, Bernier NJ, Peyon P \& Peter RE 2000 Brain regulation of feeding behavior and food intake in fish. Comparative Biochemistry and Physiology. Part A, Molecular \& Integrative Physiology 126 415-434. (doi:10.1016/S1095-6433(00)00230-0)

Malendowicz LK, Ziolkowska A \& Rucinski M 2012 Neuromedins U and S involvement in the regulation of the hypothalamo-pituitary-adrenal axis. Frontiers in Endocrinology 3 156. (doi:10.3389/fendo.2012.00156)

Maruyama K, Konno N, Ishiguro K, Wakasugi T, Uchiyama M, Shioda S \& Matsuda K 2008 Isolation and characterisation of four cDNAs encoding neuromedin $\mathrm{U}(\mathrm{NMU})$ from the brain and gut of goldfish, and the inhibitory effect of a deduced NMU on food intake and locomotor activity. Journal of Neuroendocrinology 20 71-78. (doi:10.1111/j.13652826.2007.01615.x)

Matsuda K, Sakashita A, Yokobori E \& Azuma M 2012 Neuroendocrine control of feeding behavior and psychomotor activity by neuropeptide $Y$ in fish. Neuropeptides 46 275-283. (doi:10.1016/j.npep.2012.09.006)

Minamino N, Kangawa K \& Matsuo H 1985 Neuromedin U-8 and U-25: novel uterus stimulating and hypertensive peptides identified in porcine spinal cord. Biochemical and Biophysical Research Communications 130 1078-1085. (doi:10.1016/0006-291X(85)91726-7)

Mitchell JD, Maguire JJ \& Davenport AP 2009 Emerging pharmacology and physiology of neuromedin $U$ and the structurally related peptide neuromedin S. British Journal of Pharmacology 158 87-103. (doi:10.1111/j.1476-5381.2009.00252.x)

Mori K, Miyazato M, Ida T, Murakami N, Serino R, Ueta Y, Kojima M \& Kangawa K 2005 Identification of neuromedin $S$ and its possible role in the mammalian circadian oscillator system. EMBO Journal 24 325-335. (doi:10.1038/sj.emboj.7600526)

Mori K, Miyazato M \& Kangawa K 2008 Neuromedin S: discovery and functions. Results and Problems in Cell Differentiation 46 201-212. (doi:10.1007/400_2007_054)

Nagarajan G, Aruna A \& Chang CF 2013 Neurosteroidogenic enzymes and their regulation in the early brain of the protogynous grouper Epinephelus coioides during gonadal sex differentiation. General and Comparative Endocrinology 181 271-287. (doi:10.1016/j.ygcen.2012.10.013)

Nakahara K, Katayama T, Maruyama K, Ida T, Mori K, Miyazato M, Kangawa K \& Murakami N 2010 Comparison of feeding suppression by the anorexigenic hormones neuromedin $\mathrm{U}$ and neuromedin $\mathrm{S}$ in rats. Journal of Endocrinology 207 185-193. (doi:10.1677/JOE-10-0081)

Novak CM 2009 Neuromedin S and U. Endocrinology 150 2985-2987. (doi:10.1210/en.2009-0448)

Peier A, Kosinski J, Cox-York K, Qian Y, Desai K, Feng Y, Trivedi P, Hastings N $\&$ Marsh DJ 2009 The antiobesity effects of centrally administered neuromedin $\mathrm{U}$ and neuromedin $\mathrm{S}$ are mediated predominantly by the neuromedin U receptor 2 (NMUR2). Endocrinology 150 3101-3109. (doi:10.1210/en.2008-1772)

Pepels PP, Meek J, Wendelaar Bonga SE \& Balm PH 2002 Distribution and quantification of corticotropin-releasing hormone (CRH) in the brain of the teleost fish Oreochromis mossambicus (tilapia). Journal of Comparative Neurology 453 247-268. (doi:10.1002/ cne.10377)

Quan H, Funabashi T \& Kimura F 2004 Intracerebroventricular injection of corticotropin-releasing hormone receptor antagonist blocks the suppression of pulsatile luteinizing hormone secretion induced by neuromedin $\mathrm{U}$ in ovariectomized rats after 48 hours of fasting. Neuroscience Letters 369 33-38. (doi:10.1016/j.neulet.2004.07.038)

Shousha S, Nakahara K, Sato M, Mori K, Miyazato M, Kangawa K \& Murakami N 2006 Effect of neuromedin S on feeding regulation in the Japanese quail. Neuroscience Letters 391 87-90. (doi:10.1016/j.neulet. 2005.08.033)

Southey BR, Amare A, Zimmerman TA, Rodriguez-Zas SL \& Sweedler JV 2006 NeuroPred: a tool to predict cleavage sites in neuropeptide precursors and provide the masses of the resulting peptides. Nucleic Acids Research 34 267-272. (doi:10.1093/nar/gkl161)

Tang ZG, Sun CY, Yan AF, Wu SG, Qin CB, Zhang YH \& Li WS 2013 Genes involved in fatty acid metabolism: molecular characterization and hypothalamic mRNA response to energy status and neuropeptide $\mathrm{Y}$ treatment in the orange-spotted grouper Epinephelus coioides. Molecular and Cellular Endocrinology 376 114-124. (doi:10.1016/j.mce. 2013.06.020)

Thompson JD, Higgins DG \& Gibson TJ 1994 CLUSTAL W: improving the sensitivity of progressive multiple sequence alignment through sequence weighting, position-specific gap penalties and weight matrix choice. Nucleic Acids Research 22 4673-4680. (doi:10.1093/nar/22.22.4673)

Vigo E, Roa J, López M, Castellano JM, Fernandez-Fernandez R, Navarro VM, Pineda R, Aguilar E, Diéguez C, Pinilla L et al. 2007a Neuromedin s as novel putative regulator of luteinizing hormone secretion. Endocrinology 148 813-823. (doi:10.1210/en.2006-0636)

Vigo E, Roa J, Pineda R, Castellano JM, Navarro VM, Aguilar E, Pinilla L \& Tena-Sempere M 2007b Novel role of the anorexigenic peptide neuromedin $\mathrm{U}$ in the control of LH secretion and its regulation by gonadal hormones and photoperiod. American Journal of Physiology. Endocrinology and Metabolism 293 E1265-E1273. (doi:10.1152/ajpendo. 00425.2007)

Volkoff H, Canosa LF, Unniappan S, Cerdá-Reverter JM, Bernier NJ, Kelly SP \& Peter RE 2005 Neuropeptides and the control of food intake in fish. General and Comparative Endocrinology 142 3-19. (doi:10.1016/j.ygcen. 2004.11.001)

Yan AF, Zhang LJ, Tang ZG, Zhang YH, Qin CB, Li B, Li WS \& Lin HR 2011 Orange-spotted grouper (Epinephelus coioides) orexin: molecular cloning, tissue expression, ontogeny, daily rhythm and regulation of NPY gene expression. Peptides 32 1363-1370. (doi:10.1016/j.peptides.2011. 05.004)

Yang GH, Su J, Yao Y, Lei ZH, Zhang GR \& Li X 2010 The regulatory mechanism of neuromedin $S$ on luteinizing hormone in pigs. Animal Reproduction Science 122 367-374. (doi:10.1016/j.anireprosci. 2010.10.011)

Received in final form 3 July 2015

Accepted 10 July 2015

Accepted Preprint published online 10 July 2015 http://jme.endocrinology-journals.org

DOI: 10.1530/JME-15-0018
(C) 2015 Society for Endocrinology Printed in Great Britain
Published by Bioscientifica Ltd. 